\title{
The Association between Difficulty Seeing and Physical Activity among 17,777 Adults Residing in Spain
}

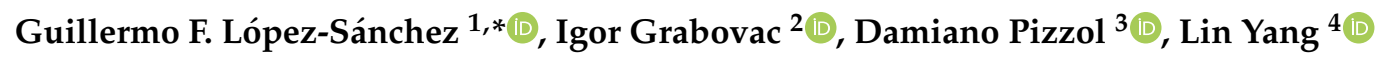 \\ and Lee Smith ${ }^{5}$ \\ 1 Faculty of Sport Sciences, University of Murcia, 30720 Murcia, Spain \\ 2 Department of Social and Preventive Medicine, Center for Public Health, Medical University of Vienna, \\ 1090 Vienna, Austria; igor.grabovac@meduniwien.ac.at \\ 3 Italian Agency for Development Cooperation, Jerusalem 9135400, Israel; damianopizzol8@gmail.com \\ 4 Cancer Epidemiology and Prevention Research, Alberta Health Services, Calgary, AB T2S 3C3, Canada; \\ lin.yang@ahs.ca \\ 5 Cambridge Centre for Sport and Exercise Science, Anglia Ruskin University, Cambridge CB1 1PT, UK; \\ Lee.Smith@anglia.ac.uk \\ * Correspondence: gfls@um.es
}

Received: 14 October 2019; Accepted: 31 October 2019; Published: 3 November 2019

\begin{abstract}
This is the first representative population-based study exploring the association between difficulty seeing (i.e., low vision) and physical activity in Spain. Cross-sectional data from the Spanish National Health Survey 2017 were analysed ( $n=17,777, \geq 15$ years; 52\% females). Difficulty seeing was self-reported in response to the question "Do you have difficulty seeing?" The international physical activity questionnaire (IPAQ) short form was used to measure level of physical activity. Multivariable logistic regression was used to assess associations overall and by age group (15-49, 50-64, $\geq 65$ years). Covariates included in the analysis were sex, age, education, marital status, use of glasses or contact lenses, cataracts, diabetes, obesity, hypertension, smoking and alcohol consumption. The overall prevalence of difficulty seeing was $11 \%$, and the overall prevalence of participating in less than 600 metabolic equivalent (MET)-min/week of physical activity was $30.2 \%$. After adjustment for covariates, difficulty seeing was associated with significantly higher odds of performing less than $600 \mathrm{MET}$-min/week of physical activity with the odds ratio (OR) $=1.222$ (95\% confidence interval $=1.099-1.357)$. Considering the impact on health and quality of life due to reduced physical activity in people with difficulty seeing, at least $600 \mathrm{MET}-\mathrm{min} /$ week of physical activity should be promoted to this population.
\end{abstract}

Keywords: vision problems; diabetic eye disease; physical activity; public health

\section{Introduction}

In Europe, in 2010, there were 2,550,000 people who were blind and a further 23,800,000 with low vision resulting in 26,350,000 visually impaired individuals [1]. In addition, approximately 1.3 billion people globally live with distance or near vision impairment [1].

Influences on aetiology leading to vision impairment are multi-faceted, including increasing age [2], sex (women have been shown to be at higher risk than men) [3,4], higher lifetime ultra-violet exposure [5], systemic diseases (e.g., hypertension) [6,7], diabetes [7,8] or lower levels of education [3,9].

Vision impairment is a key barrier to the practice of physical activity in adults [10]. This makes it difficult for adults with vision problems to achieve the recommendation of at least 600 metabolic equivalent (MET)-min/week or 150 min of moderate-intensity activity over a week [11]. 
In fact, a small body of literature provides preliminary evidence that low vision is associated with lower levels of physical activity. A recent study, of older English adults $(n=6634)$, found that those with low vision were over twice as likely to be physically inactive compared with those with excellent vision [12]. Similarly, another study, with a sample of 6001 participants residing in the United States of America (USA), also suggests that visual impairment is associated with lower levels of physical activity [13]. Research has also found that children with low vision do less physical activity than those with good vision [14-18].

Considering the negative effects of visual impairment and physical inactivity on the quality of life and functional capacity of people, as well as the association between these two variables found in some previous studies, new population-based epidemiological studies exploring these links are needed. Specifically, in previously unreported countries, where the social and political context, physical environments (e.g. exposure to sunlight), and lifestyle behaviours, likely influencing these variables, are different

Several studies in the past two decades have investigated the prevalence of low vision in Spain. A cross-sectional observational study including 1155 elderly from the province of Cuenca estimated that the prevalence of visual impairment and blindness in the sample was $6.3 \%$ and $2.0 \%$, respectively [19]. These findings were corroborated in a second study of 15,926 adults from Catalonia, as low vision was reported by $5.3 \%$ of women and $4.1 \%$ of men [20]. However, to the best of our knowledge, there are no representative population-based studies exploring the association between visual impairment and physical activity in Spain. Therefore, it is the aim of this study to explore the associations between the prevalence of visual impairment and the levels of physical activity in a Spanish population.

\section{Methods}

\subsection{The Survey}

Data from the Spanish National Health Survey 2017 were analysed. This survey was undertaken in Spain between October 2016 and October 2017. Details of the survey method are published elsewhere [21]. In brief, for the data collection, a stratified three-stage sampling was used in which the census sections were first considered, followed by the family dwellings and then an adult (15 years of age or more) was selected within each dwelling. The dwellings were selected by systematic sampling, and to select the person who had to complete the adult questionnaire, the random Kish method was used. The sample was representative of the adult population residing in Spain and consisted of 17,777 adults aged 15-69 years. The age group of adults $\geq 70$ years was not considered in this study, as they did not complete the international physical activity questionnaire (IPAQ) short form. The IPAQ short form was developed for population surveillance of physical activity among adults aged 15-69 years. However, the use of the IPAQ with older and younger age groups is not recommended [22]. The method of data collection used was computer-assisted personal interviewing (CAPI), conducted in the homes of the selected participants. The interviewers, previously trained, completed the questionnaires with the information provided by the participants. All of them signed an informed consent form before responding to the survey questions. This research was conducted in accordance with the Declaration of Helsinki of 1961 (revised in Tokyo in 1989 and in Edinburgh in 2000).

\subsection{Difficulty Seeing (Exposure)}

Those who answered affirmatively to the question "Do you have difficulty seeing?" were considered to have difficulty seeing (i.e., visual impairment). In the case of those participants that used glasses or contact lenses, they were asked if they had difficulty seeing using their glasses or contact lenses. 


\subsection{Physical Activity (Outcome)}

The IPAQ short form was used to measure physical activity. Total physical activity MET-min/week was calculated via the sum of walking + moderate + vigorous MET-min/week scores [22]. Participants were divided according to the guidelines for data processing and analysis of the IPAQ into (1) fewer than $600 \mathrm{MET}-\mathrm{min} /$ week and (2) at least $600 \mathrm{MET}-\mathrm{min} /$ week [20], equivalent to meeting the current physical activity recommendation. IPAQ has been validated in adult populations from different countries showing acceptable validity ( $\rho=0.30,95 \%$ CI: $0.23-0.36$ ) and reliability (Spearman's $\rho=0.81,95 \%$ CI: $0.79-0.82$ ) [23].

\subsection{Covariates}

Covariates were selected based on findings from the literature [12,13,24]. Sociodemographic covariates included in the models were sex, age, marital status and education. Education was categorised as $\leq$ primary, secondary and $\geq$ tertiary. Height and weight were self-reported. Body mass index (BMI) was calculated as weight in kilograms divided by height in meters squared. Obesity was defined as BMI $\geq 30 \mathrm{~kg} / \mathrm{m}^{2}$. Participants who responded yes to the questions "Have you ever been diagnosed with diabetes/hypertension/cataracts?" were categorized as having diabetes/hypertension/cataracts. Those who answered affirmatively to the question "Do you use glasses or contact lenses?" were considered to use glasses or contact lenses. Smoking status was self-reported and categorised as never, current smoker or former smoker. Alcohol consumption in the last 12 months was self-reported and categorised as yes (any) or no (none).

\subsection{Statistical Analysis}

The statistical analysis was performed with SPSS 23.0 (IBM, Armonk, NY, USA). Differences in the prevalence of difficulty seeing by sample characteristics were assessed by Chi-squared tests. We conducted a multivariable logistic regression analysis to assess the association between difficulty seeing (exposure) and physical activity (outcome). Analyses were conducted for the overall sample and separately by age group $(15-49,50-64$ and $\geq 65$ years). All analyses were adjusted for sex, marital status, education, use of glasses or contact lenses, cataracts, diabetes, obesity, hypertension, smoking and alcohol consumption. The whole-sample analysis was also adjusted for age. All variables were included in the models as categorical variables. There were missing data only on the following variables: obesity $(2.8 \%)$, smoking $(0.1 \%)$ and alcohol consumption $(0.1 \%)$. Complete case analysis was carried out. Results from the logistic regression analyses are presented as odds ratios (ORs) with $95 \%$ CIs. The level of statistical significance was set at $p<0.05$.

\section{Results}

The sample consisted of 17,777 adults residing in Spain. The age range of the sample was 15-69 years, and the mean (standard deviation (SD)) age was 45.8 (14.1) years. $52 \%$ of the sample were female. The total average physical activity of the sample was $2263.7 \pm 3222.9$ MET-min/week $(2025.2 \pm 3374.7$ MET-min/week in those with difficulty seeing and 2293.1 \pm 3202.7 MET-min/week in those without difficulty seeing). The overall prevalence of difficulty seeing was $11 \%$, and the overall prevalence of people doing less than 600 MET-min/week of physical activity was $30.2 \%$. Overall, the prevalence of difficulty seeing among those doing less and more than 600 MET-min/week of physical activity was $13.4 \%$ and $9.9 \%$, respectively. Overall, the prevalence of people doing less than 600 MET-min/week of physical activity among those with and without difficulty seeing was $36.9 \%$ and $29.4 \%$, respectively. A linear increase in the prevalence of people doing less than 600 MET-min/week of physical activity was observed among those with difficulty seeing with increasing age. A decrease in this prevalence was observed among those without difficulty seeing who were older than 65 years (Figure 1).

Based on unadjusted estimates, ages between 50 and 64 years, female sex, being married, lower education, obesity, diabetes, hypertension, cataracts, smoking, no alcohol consumption and difficulty 
seeing were associated with significantly higher prevalence of doing less than 600 MET-min/week of physical activity (Table 1).

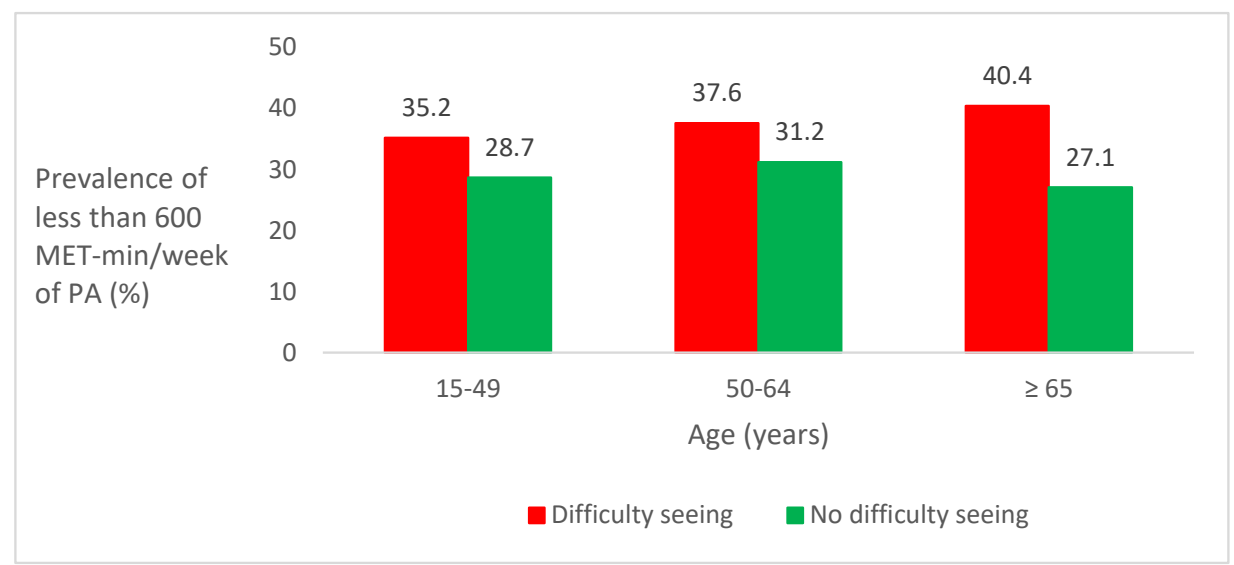

Figure 1. Prevalence of less than 600 metabolic equivalent (MET)-min/week of physical activity (PA) by age groups in those with and without difficulty seeing.

Table 1. Sample characteristics.

\begin{tabular}{|c|c|c|c|c|c|c|}
\hline Characteristic & Category & $n$ & Column \% & $\begin{array}{r}n(\%) \\
600 \mathrm{MET}\end{array}$ & $\begin{array}{l}s \text { than } \\
k \text { of PA }\end{array}$ & $p$-Value ${ }^{b}$ \\
\hline \multirow{3}{*}{ Age (years) } & $15-49$ & 10,089 & 56.8 & 2950 & $(29.2)$ & \multirow{3}{*}{$<0.001$} \\
\hline & $50-64$ & 5977 & 33.6 & 1915 & $(32.0)$ & \\
\hline & $\geq 65$ & 1711 & 9.6 & 501 & $(29.3)$ & \\
\hline \multirow[b]{2}{*}{ Sex } & Female & 9248 & 52.0 & 2990 & $(32.3)$ & \multirow[b]{2}{*}{$<0.001$} \\
\hline & Male & 8529 & 48.0 & 2376 & $(27.9)$ & \\
\hline \multirow{2}{*}{ Marital status } & Married & 10,010 & 56.3 & 3189 & $(31.9)$ & \multirow{2}{*}{$<0.001$} \\
\hline & $\begin{array}{c}\text { Not } \\
\text { married }\end{array}$ & 7767 & 43.7 & 2177 & $(28.0)$ & \\
\hline \multirow{3}{*}{ Education } & $\leq$ Primary & 3324 & 18.7 & 1303 & $(39.2)$ & \multirow{3}{*}{$<0.001$} \\
\hline & Secondary & 9004 & 50.6 & 2712 & $(30.1)$ & \\
\hline & $\geq$ Tertiary & 5449 & 30.7 & 1351 & $(24.8)$ & \\
\hline \multirow{3}{*}{ Obesity (BMI $\geq 30 \mathrm{~kg} / \mathrm{m}^{2}$ ) } & No & 14,424 & 83.5 & 3992 & $(27.7)$ & \multirow{3}{*}{$<0.001$} \\
\hline & Yes & 2849 & 16.5 & 1137 & $(39.9)$ & \\
\hline & Missing & 504 & & & & \\
\hline \multirow[b]{2}{*}{ Diabetes } & No & 16,763 & 94.3 & 5007 & $(29.9)$ & \multirow[b]{2}{*}{$<0.001$} \\
\hline & Yes & 1014 & 5.7 & 359 & $(35.4)$ & \\
\hline \multirow{2}{*}{ Hypertension } & No & 14,633 & 82.3 & 4261 & $(29.1)$ & \multirow{2}{*}{$<0.001$} \\
\hline & Yes & 3144 & 17.7 & 1105 & $(35.1)$ & \\
\hline \multirow{2}{*}{ Cataracts } & No & 17,113 & 96.3 & 5113 & $(29.9)$ & \multirow{2}{*}{$<0.001$} \\
\hline & Yes & 664 & 3.7 & 253 & $(38.1)$ & \\
\hline \multirow{2}{*}{ Glasses or contact lenses } & No & 6653 & 37.4 & 1996 & $(30.0)$ & \multirow{2}{*}{0.680} \\
\hline & Yes & 11,124 & 62.6 & 3370 & $(30.3)$ & \\
\hline \multirow{4}{*}{ Smoking } & Never & 8198 & 46.1 & 2355 & (28.7) & \multirow{4}{*}{$<0.001$} \\
\hline & Current & 5071 & 28.5 & 1737 & $(34.3)$ & \\
\hline & Former & 4497 & 25.3 & 1265 & $(28.1)$ & \\
\hline & Missing & 11 & & & & \\
\hline \multirow{3}{*}{ Alcohol Consumption } & No & 5371 & 30.2 & 1853 & $(34.5)$ & \multirow{3}{*}{$<0.001$} \\
\hline & Yes & 12,392 & 69.8 & 3505 & $(28.3)$ & \\
\hline & Missing & 14 & & & & \\
\hline \multirow{2}{*}{ Difficulty seeing } & No & 15,828 & 89.0 & 4646 & $(29.4)$ & \multirow{2}{*}{$<0.001$} \\
\hline & Yes & 1949 & 11.0 & 720 & (36.9) & \\
\hline
\end{tabular}

Notes: MET (Metabolic Equivalent of Task). BMI (body mass index). a Number (and percentage) of individuals with that sample characteristic who do less than 600 MET-min/week of physical activity. ${ }^{b} p$-value was calculated with Chi-squared tests. 
In the adjusted overall analysis, difficulty seeing was associated with significantly higher odds for those doing less than 600 MET-min/week of physical activity (OR $=1.222,95 \% \mathrm{CI}=1.099-1.357$ ) (Table 2). Lower age, female sex, being married, lower education, obesity, hypertension, smoking and no alcohol consumption were also associated with significantly higher odds of doing less than 600 MET-min/week of physical activity (Table 2). A final adjusted overall analysis was carried out considering only these previous variables associated with significantly higher odds of doing less than $600 \mathrm{MET}-\mathrm{min} /$ week of physical activity. In this case, difficulty seeing was also associated with significantly higher odds of doing less than 600 MET-min/week of physical activity $(\mathrm{OR}=1.218$, $95 \%$ CI $=1.097-1.353$ ).

Table 2. Association of difficulty seeing and other covariates with physical activity (outcome) estimated by multivariable logistic regression. $(n=17,777)$.

\begin{tabular}{cccc}
\hline \multicolumn{2}{c}{ Characteristic } & Less than 600 MET-Min/Week of Physical Activity \\
\hline Difficulty seeing & Yes vs. No & $1.222^{* * *}$ & $(1.099,1.357)$ \\
\hline Age (years) & $15-49$ & $1.515^{* * *}$ & $(1.317,1.742)$ \\
& $50-64$ & $1.378^{* * *}$ & $(1.211,1.569)$ \\
\hline Sex & $\geq 65$ & $1.272^{* * *}$ & $(1.187,1.364)$ \\
\hline Marital status & Male vs. Female & $1.236^{* * *}$ & $(1.154,1.324)$ \\
\hline Education & Married vs. Not married & $1.763^{* * *}$ & $(1.587,1.959)$ \\
\hline Obesity & Secondary & $1.235^{* * *}$ & $(1.140,1.338)$ \\
\hline Diabetes & $\geq$ Tertiary & 1.0 & $(1.469,1.752)$ \\
\hline Hypertension & Yes vs. No & $1.605^{* * *}$ & $(0.875,1.173)$ \\
\hline Cataracts & Yes vs. No & 1.013 & $(1.050,1.270)$ \\
\hline Glasses or contact lenses & Yes vs. No & $1.154^{* *}$ & $(1.050,1.495)$ \\
\hline Smoking & Yes vs. No & $1.253^{*}$ & $(0.947,1.106)$ \\
\hline Alcohol consumption & Yes vs. No & 1.023 & $(1.287,1.511)$ \\
\hline Notes: Estimates are odds ratio $\left(95^{*}\right.$ confidence interval). Models are adjusted for all variables in the table. ${ }^{*} p<0.05$.
\end{tabular}

Age-stratified analyses showed that the association between difficulty seeing and physical activity was significant among those from 15 to 49 years old $(\mathrm{OR}=1.200,95 \% \mathrm{CI}=1.027-1.402)$ and among those older than 65 years $(\mathrm{OR}=1.508,95 \% \mathrm{CI}=1.124-2.023)$ (Table 3). This association was also significant when the analyses were adjusted only for the variables significantly associated with less than $600 \mathrm{MET}-\mathrm{min} /$ week of physical activity for $15-49$ years old $(\mathrm{OR}=1.198 ; 95 \% \mathrm{CI}=1.026-1.400)$ and older than 65 years $(\mathrm{OR}=1.479,95 \% \mathrm{CI}=1.105-1.979)$.

Table 3. Association of difficulty seeing and physical activity (outcome) by age groups estimated with multivariable logistic regression. ( $n=17,777)$.

\begin{tabular}{ccc}
\hline Age (Years) & \multicolumn{2}{c}{$\begin{array}{c}\text { Association between Difficulty Seeing and Less than } \\
\text { 600 MET-Min/Week of Physical Activity (Outcome) }\end{array}$} \\
\hline $15-49$ & $1.200 *$ & $(1.027,1.402)$ \\
$50-64$ & 1.149 & $(0.972,1.358)$ \\
$\geq 65$ & $1.508^{* *}$ & $(1.124,2.023)$ \\
\hline
\end{tabular}

Notes: Estimates are odds ratio (95\% CI). Models are adjusted for sex, marital status, education, obesity, diabetes, hypertension, cataracts, use of glasses or contact lenses, smoking and alcohol consumption. ${ }^{*} p<0.05,{ }^{* *} p<0.01$. 


\section{Discussion}

To our knowledge, this is the first Spanish representative population-based study exploring the association between prevalence of difficulty seeing and physical activity. In this Spanish sample, the overall prevalence of participating in less than 600 MET-min/week of physical activity was 30.2\%. These results are similar to those of the World Health Organization [25], which states that, globally, $27.5 \%$ of adults are insufficiently physically active. The overall prevalence of difficulty seeing in this Spanish sample was 11\%, which is not high in comparison with a similar population-based study in the USA (33.8\% uncorrected refractive error and 5.4\% non-refractive visual impairment) [13]. The differences in these prevalence rates are likely to be due to differences in population characteristics, such as different ages [2], different sex distribution [3,4], different prevalence of systemic diseases (e.g., hypertension) [6,7], different prevalence of diabetes [7,8] or lower levels of education [3,9], as well as differences in the methods used between the studies.

The multivariable logistic regression showed that difficulty seeing was associated with $22.4 \%$ increased odds of doing less than $600 \mathrm{MET}-\mathrm{min} /$ week of physical activity. These results concur with other studies that have found negative associations between visual problems and physical activity in adults [12,13,26-28]. However, the association found in Spanish adults was weaker than in some previous studies. For example, a recent study, of older English adults $(n=6634)$, found that those with low vision were over twice as likely to be physically inactive compared with those with excellent vision [12]. Previous studies have indicated that the main barriers to an active lifestyle in people with difficulty seeing are lack of access to recreational and athletic programmes, lack of transport, lack of accessible exercise equipment, lack of help or encouragement in developing suitable and safe physical recreation skills and habits and activity limitations in walking [10,29]. Interventions that address these barriers to physical activity participation and that promote group physical activity [30] are required to increase activity levels in the Spanish population with difficulty seeing.

The main strengths of this study were the large representative sample and the use of a validated, reliable and internationally recognised questionnaire to measure physical activity. However, the results of this study should be considered within its limitations. The age group of adults $\geq 70$ years was not considered, because the IPAQ short form is designed for the age range of 15-69 years. Assessment of difficulty seeing was self-reported, potentially introducing bias. This study did not include data about motor dysfunctions that could affect the amount of physical activity, and in consequence, it is recommended that this factor is considered in future studies. Moreover, the cross-sectional nature of the study means the direction of the association is not known. While we hypothesise that it is likely bidirectional, future longitudinal studies are needed to clarify the direction of causality.

\section{Conclusions}

The present study found a significant association between difficulty seeing and physical activity in a large sample of adults residing in Spain. Considering previous literature that has shown a negative impact on health and quality of life due to reduced physical activity in people with difficulty seeing, at least $600 \mathrm{MET}-\mathrm{min} /$ week of physical activity should be promoted.

Author Contributions: G.F.L.-S., I.G., D.P., L.Y. and L.S. conceived of and designed the study, analysed the data and wrote the paper.

Funding: G.F.L.-S. is funded by the Seneca Foundation-Agency for Science and Technology of the Region of Murcia, Spain. 20390/PD/17.

Conflicts of Interest: The authors declare no conflict of interest.

\section{References}

1. World Health Organization. Blindness and Vision Impairment. Available online: https://www.who.int/ blindness/en/ (accessed on 22 August 2019).

2. Liu, Y.C.; Wilkins, M.; Kim, T.; Malyugin, B.; Mehta, J.S. Cataracts. Lancet 2017, 390, 600-612. [CrossRef] 
3. Seddon, J.; Fong, D.; West, S.K.; Valmadrid, C.T. Epidemiology of risk factors for age-related cataract. Surv. Ophthalmol. 1995, 39, 323-334. [CrossRef]

4. Chatterjee, A.; Milton, R.C.; Thyle, S. Prevalence and aetiology of cataract in Punjab. Br. J. Ophthalmol. 1982, 66, 35-42. [CrossRef] [PubMed]

5. Vrensen, G.F. Early cortical lens opacities: A short overview. Acta Ophthalmol. 2009, 87, 602-610. [CrossRef]

6. Klein, B.; Klein, R.; Jensen, S.C.; Linton, K.L. Hypertension and lens opacities from the Beaver Dam Eye Study. Am. J. Ophthalmol. 1995, 119, 640-646. [CrossRef]

7. Leske, M.C.; Wu, S.Y.; Hennis, A.; Connell, A.M.; Hyman, L.; Schachat, A. Diabetes, hypertension, and central obesity as cataract risk factors in a black population: The Barbados Eye Study. Ophthalmology 1999, 106, 35-41. [CrossRef]

8. Pollreisz, A.; Schmidt-Erfurth, U. Diabetic Cataract-Pathogenesis, Epidemiology and Treatment. J. Ophthalmol. 2010, 608751, 1-8. [CrossRef]

9. Keel, S.; He, M. Risk factors for age-related cataract. Clin. Exp. Ophthalmol. 2018, 46, 327-328. [CrossRef]

10. Capella-McDonnall, M. The need for health promotion for adults who are visually impaired. J. Vis. Impair. Blind. 2007, 101, 133-145. [CrossRef]

11. NHS UK: Physical Activity Guidelines for Older Adults. Available online: https://www.nhs.uk/live-well/ exercise/physical-activity-guidelines-older-adults/ (accessed on 22 August 2019).

12. Smith, L.; Timmis, M.A.; Pardhan, S.; Latham, K.; Johnstone, J.; Hamer, M. Physical inactivity in relation to self-rated eyesight: Cross-sectional analysis from the English Longitudinal Study of Ageing. BMJ Open Ophth. 2016, 1, e000046. [CrossRef]

13. Smith, L.; Jackson, S.E.; Pardhan, S.; López-Sánchez, G.F.; Liang, H.; Cao, C.; Vancampfort, D.; Koyanagi, A.; Stubbs, B.; Firth, J.; et al. Visual impairment and objectively measured physical activity and sedentary behaviour in US adolescents and adults: A cross-sectional study. BMJ Open 2019, 9, e027267. [CrossRef] [PubMed]

14. Oh, H.K.; Ozturk, M.A.; Kozub, F.M. Physical activity and social engagement patterns during physical education of youth with visual impairments. ProQuest 2004, 36, 39e49. [CrossRef]

15. Houwen, S.; Hartman, E.; Visser, C. Physical activity and motor skills in children with and without visual impairments. Med. Sci. Sports Exerc. 2009, 41, 103-109. [CrossRef] [PubMed]

16. Harris, J.; Keil, S.; Lord, C.; Lloyd, C.L. Sight Impairment at Age Eleven: Secondary Analysis of the Millennium Cohort Survey. Available online: https://www.bl.uk/britishlibrary/ \{\}/media/bl/global/socialwelfare/pdfs/non-secure/s/i/g/sight-impairment-at-age-eleven-secondary-analysis-of-the-millenniumcohort-survey.pdf (accessed on 2 November 2019).

17. Greguol, M.; Gobbi, E.; Carraro, A. Physical activity practice, body image and visual impairment: A comparison between Brazilian and Italian children and adolescents. Res. Dev. Disabil. 2014, 35, 21-26. [CrossRef] [PubMed]

18. Williams, G.; Aggio, D.; Stubbs, B.; Pardhan, S.; Gardner, B.; Smith, L. Physical activity levels in children with sensory problems: Cross-sectional analyses from the Millennium Cohort Study. Disabil. Health J. 2018, 1, 58-61. [CrossRef]

19. Esteban, J.J.; Martínez, M.S.; Navalón, P.G.; Serrano, O.P.; Patiño, J.R.; Purón, M.E.; Martínez-Vizcaíno, V. Visual impairment and quality of life: Gender differences in the elderly in Cuenca, Spain. Qual. Life Res. 2008, 17, 37-45. [CrossRef]

20. Guisasola, L.; Tresserras-Gaju, R.; García-Subirats, I.; Rius, A.; Brugulat-Guiteras, P. Prevalence and burden of visual impairment in Catalonia, Spain. Med. Clin. (Barc) 2011, 137, 22-26. [CrossRef]

21. Ministerio de Sanidad, Servicios Sociales e Igualdad \& Instituto Nacional de Estadística: Spanish National Health Survey 2017: Methodology. Available online: https:/www.mscbs.gob.es/estadEstudios/estadisticas/ encuestaNacional/encuestaNac2017/ENSE17_Metodologia.pdf (accessed on 22 August 2019).

22. IPAQ group: Guidelines for Data Processing and Analysis of the International Physical Activity Questionnaire (IPAQ). Available online: https://sites.google.com/site/theipaq/scoring-protocol (accessed on 22 August 2019).

23. Craig, C.L.; Marshall, A.L.; Sjöström, M.; Bauman, A.E.; Booth, M.L.; Ainsworth, B.E.; Pratt, M.; Ekelund, U.; Yngve, A.; Sallis, J.F.; et al. International physical activity questionnaire: 12-Country reliability and validity. Med. Sci. Sports Exerc. 2003, 35, 1381-1395. [CrossRef]

24. Yawson, A.E.; Ackuaku-Dogbe, E.M.; Seneadza, N.A.; Mensah, G.; Minicuci, N.; Naidoo, N.; Chatterji, S.; Kowal, P.; Biritwum, R.B. Self-reported cataracts in older adults in Ghana: Sociodemographic and health related factors. BMC Public Health 2014, 14, 1-8. [CrossRef] 
25. World Health Organization. Prevalence of Insufficient Physical Activity. Available online: https://www.who. int/gho/ncd/risk_factors/physical_activity_text/en/ (accessed on 22 August 2019).

26. Zheng Selin, J.; Orsini, N.; Ejdervik Lindblad, B.; Wolk, A. Long-term physical activity and risk of age-related cataract: A population-based prospective study of male and female cohorts. Ophthalmology 2015, 122, 274-280. [CrossRef]

27. Williams, P.T. Walking and running are associated with similar reductions in cataract risk. Med. Sci. Sports Exerc. 2013, 45, 1089-1096. [CrossRef] [PubMed]

28. Williams, P.T. Prospective Epidemiological Cohort Study of Reduced Risk for Incident Cataract with Vigorous Physical Activity and Cardiorespiratory Fitness during a 7-Year Follow-up. Invest. Ophthalmol. Vis. Sci. 2009, 50, 95-100. [CrossRef] [PubMed]

29. Phoenix, C.; Griffin, M.; Smith, B. Physical activity among older people with sight loss: A qualitative research study to inform policy and practice. Public Health 2015, 129, 124-130. [CrossRef] [PubMed]

30. Trott, M.; Smith, L. What are the associations between extroversion, enjoyment, and wellness in group vs non-group physical activity? A pilot study. Atena J. Sports Sci. 2019, 1, 1-11.

(C) 2019 by the authors. Licensee MDPI, Basel, Switzerland. This article is an open access article distributed under the terms and conditions of the Creative Commons Attribution (CC BY) license (http://creativecommons.org/licenses/by/4.0/). 